\title{
Cord centrality and eccentricity indices of the placenta and their associations
}

\author{
NARAYANAN, S., MOHAMED, T. and SHANKAR, N. * \\ Department of Anatomy, St. John's Medical College, Bangalore, India \\ *E-mail: nachiket76@gmail.com
}

\begin{abstract}
Introduction: The shape of the placenta and position of umbilical cord insertion are associated with perinatal outcome. Cord centrality index (CCI) is a measure of the distance of the umbilical cord insertion from the center of the placenta. Eccentricity index (EI) is a measure of placental shape. Hyrtl's anastomosis (HA) connects the two umbilical arteries and helps to equalize pressure differences. The hypothesis of the study was that there would be a significant correlation between the diameter of HA and the CCI and EI. Materials and Methods: The maximum length, maximum breadth, and distance of the umbilical cord insertion from the center were estimated using Image J software on superior view digital photographs of 88 placentae. The CCI and EI were then calculated. Relevant diameters were measured, and the twist of each umbilical cord was categorized as left and right. Strength of association was estimated using Spearman's correlation, and the independent sample T test for estimating group differences. Results: The mean values of the CCI and EI were $0.41 \pm 0.19$ and $0.42 \pm 0.17$. A significant correlation was noted with the diameter of HA between both CCI $(0.237, \mathrm{p}=0.029)$ and EI $(-0.252, \mathrm{p}=0.020)$. No significant differences were observed in the CCI and EI between cords with right and left twist. Conclusion: A greater diameter of the HA is likely be indicative of a higher difference in the blood flow between the umbilical arteries which in turn could influence the placental shape and umbilical cord insertion.
\end{abstract}

Keywords: placenta, cord centrality index, eccentricity index, umbilical cord twist, Hyrtl's anastomosis.

\section{Introduction}

In clinical practice, the shape of the placenta varies from round to oval, or irregular. The shape of the placenta is thought to be influenced by various factors including the placental vascular pattern (YAMPOLSKY, SALAFIA, SHLAKHTER et al., 2008). It has been quantified by using an index called the eccentricity index (EI). The umbilical cord insertion on to the placenta has been categorized into central, eccentric, marginal and velamentous. A marginal insertion is more susceptible to vessel rupture and has been associated with adverse perinatal outcomes. An index called the cord centrality index (CCI) has been developed to estimate the position of insertion of the umbilical cord (PATHAK, HOOK, HACKETT et al., 2010).

The umbilical cord usually has a left sided twist. A right sided twist is often associated with the presence of a single umbilical artery and placenta previa (QIN, LAU and ROGERS, 2002). In the umbilical cord, the arteries also exhibit coiling within the Wharton's jelly and are connected by the Hyrtl's anastomosis (HA) (Figure 1). The functional significance of the HA is to equalize the pressure differences between the two umbilical arteries thereby maintaining uniform blood distribution across the placenta. It also acts as a safety valve if one of the umbilical arteries is compressed (BAERGEN, 2005).

The aim was to study the influence of the diameter of HA (as an indicator of asymmetry in the size of the umbilical cord arteries) on the shape of the placenta and position of the umbilical cord insertion. The hypothesis of the study was that there would be a significant correlation between the diameter of HA and the CCI and EI. The objectives of the study were to estimate the following: 1. CCI and EI; 2. Strength of association between the indices and diameter of HA; 3 . Difference in the indices between cords with right and left twist.

\section{Short Communication}

This was a cross sectional analytical study. One hundred and fifty placentae were available in the Department of Anatomy of a tertiary care medical college hospital in South India. Of these, 88 singleton placentae were included in the study. The remaining placentae were either damaged or fused and were excluded. No formal sample size calculation was performed, as this was a pilot study with no previous available data. The study was exempted from clearance by the Institutional Ethics Review Board.

The placentae were preserved in 10\% formalin. The direction of twist of the umbilical cord was determined by placing it vertically and using the limbs of the capital letter V. Umbilical cords with left twist and right twist had grooves of coiling parallel to the respective limbs of the V (FINBERG, 1992). A longitudinal incision was made close to the distal end of the umbilical cord. The umbilical arteries were cleared from the surrounding Wharton's jelly and the HA was identified and cleaned (Figure 1). The external diameter of HA was measured using digital Vernier calipers with an accuracy of $0.01 \mathrm{~mm}$.

The placentae were washed properly to remove blood clots. They were then placed over an osteometric board in such a way that the fetal surface faced upwards. The umbilical cord attachment was placed towards the right lower quadrant of the photographic field whenever there was an eccentric or marginal 

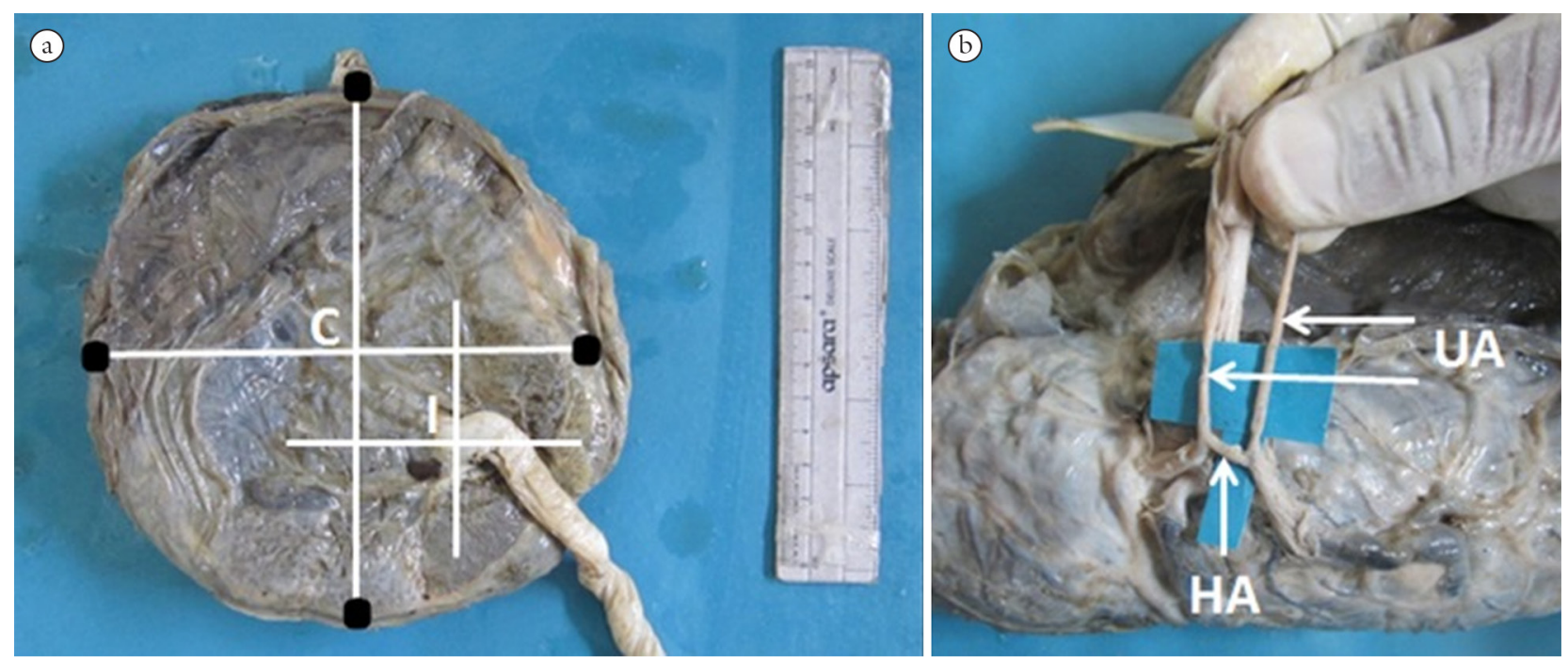

Figure 1. (a) The lines drawn to calculate CCI and EI; (b) Demonstration of Hyrtl's anastomosis. C: center of the placenta; HA: Hyrtl's anastomosis; I: umbilical cord insertion; UA: umbilical arteries.

attachment. A ruler with centimeter markings was placed in the photographic field for the purpose of calibration. A digital camera with 12 megapixel resolution was fixed to the osteometric board at a uniform distance of $20 \mathrm{~cm}$ from the placentae to minimize errors of parallax. Superior view photographs were taken and transferred to PowerPoint software (version 2010). Lines were drawn to represent the maximum length $(\mathrm{L})$ and breadth (B) of the placentae (Figure 1). The center (C) of the placenta was defined as the intersection between $\mathrm{L}$ and $\mathrm{B}$. The longest diameter (major axis) was either L or B depending upon which was greater. The other diameter was termed the minor axis. Two lines parallel to $\mathrm{L}$ and $\mathrm{B}$ were drawn such that they intersected at the point of the umbilical cord insertion (I). Images were analyzed using Image J software [version 1.48d].

The CCI was calculated using the following formula (PATHAK, HOOK, HACKETT et al., 2010):

$$
\text { Cord Centrality Index }(\mathrm{CCI})=\frac{\begin{array}{c}
\text { Distance of umbilical cord } \\
\text { insertion from placental center }
\end{array}}{\begin{array}{c}
\text { Half of the longest diameter } \\
\text { of the placenta }
\end{array}}
$$

The EI was calculated using the following formula:

$$
\text { Eccentricity Index }(E I)=\sqrt{1-(\text { minor axis/major axis })}
$$

The mean and standard deviation of the EI, CCI and HA were calculated. The Shapiro-Wilk test for normality was performed for EI, CCI and HA. Spearman's correlation coefficient was used to estimate the strength of association between the indices and the diameter of HA. The difference in the indices between umbilical cords with right and left twist was estimated using the Mann Whitney U test. A P value of less than 0.05 was considered statistically significant.

The mean values of the CCI and EI were $0.41 \pm 0.19$ (range, 0.15 to 1 ) and $0.42 \pm 0.17$ (range, 0.15 to 0.9 ). The mean value of the diameter of HA was $2.6 \pm 1.3 \mathrm{~mm}$ (range, 1.14 to 7.72 ). The values of the CCI and diameter of HA were not normally distributed. The diameter of HA was found to be significantly correlated with both CCI (rho $=0.237, \mathrm{p}=0.029)$ and EI (rho $=-0.252, \mathrm{p}=0.020)$.

The proportion of umbilical cords with a left and right twist were 71 of $88(80.7 \%)$ and 17 of $88(19.3 \%)$ respectively. The mean of the CCI in umbilical cords with a left and right twist were $0.41 \pm 0.21$ and $0.47 \pm 0.16$ respectively. Similar values for the EI were $0.43 \pm 0.18$ and $0.39 \pm 0.14$. No significant differences were observed in the CCI $(\mathrm{P}=0.143)$ and EI $(\mathrm{P}=0.369)$ between cords with right and left twist.

\section{Discussion}

The EI is defined as the ratio of the distance between the foci to the length of the major axis. The value of EI varies between 0 and 1 . A value of 0 indicates that the shape of the placenta is circular, while values nearer 1 indicate an elliptical shape (PATHAK, HOOK, HACKETT et al., 2010). In the present study, a mean EI of $0.42 \pm 0.17$ suggests that the commonly occurring shape of the placenta is neither spherical nor elliptical. A previous study done in the United Kingdom on 861 normal singleton placentae showed a mean EI of $0.49 \pm 0.17$ (PATHAK, HOOK, HACKETT et al., 2010). However another study done on 207 singleton placentae in Ghana showed higher mean values of $0.85 \pm 0.10$ for the EI (BIMPONG, 2012).

Significant negative correlation between EI and the diameter of HA indicates that when there is an increase in diameter of $\mathrm{HA}$, the placental shape tends to be more circular. The shape of the placenta is influenced by the placental vasculature (SALAFIA, YAMPOLSKY, MISRA et al., 2010). It is reasonable to assume that the diameter of HA would be influenced by the asymmetry in the sizes of the two umbilical arteries. This in turn could influence the shape of the placenta. The correlation coefficients obtained in the present study though significant were small. It is therefore likely that other factors influence the shape of the placenta such as the site of implantation, regional variations in the decidua and variations in maternal vascular supply (BAERGEN, 2005). Genetic and racial factors may also contribute, as evidenced by the much higher EI seen in the study conducted in Ghana. 
The CCI is defined as the ratio that describes the distance of the umbilical cord insertion from the chorionic plate margin. The value of CCI varies from 0 and 1 . Smaller the CI, closer is the umbilical cord insertion to the placental center (PATHAK, HOOK, HACKETT et al., 2010). In the present study, a mean CCI of $0.41 \pm 0.19$ suggest that the umbilical cord is attached eccentrically in a majority of the placentae. Previous studies have noted mean CCI values of $0.36 \pm 0.21$ (PATHAK, HOOK, HACKETT et al., 2010) and $0.53 \pm 0.56$ (BIMPONG, 2012).

A significant positive correlation between the CCI and diameter of HA indicates that when there is an increase in diameter of HA, the umbilical cord attachment tends be more peripheral. The variation in the site of umbilical cord insertion is due to a process called trophotropism in which the chorion frondosum or the early placenta "migrates" with advancing gestation to ensure a better blood supply from a more richly vascularized area (ROBINSON, JONES and BENIRSCHKE, 1983). A greater diameter of the HA is likely be indicative of a higher difference in the blood flow between the umbilical arteries. This in turn could influence the position of attachment of the umbilical cord.

Absence of HA can result in discordant umbilical arteries, a condition often associated with velamentous and marginal insertion of the umbilical cord (RAIO, GHEZZI, DI NARO et al., 1998). A previous angiographic study had noted a mean diameter of the HA being $2.4 \mathrm{~mm}$ (ULLBERG, LINGMAN, EKMAN-ORDEBERG et al., 2003), Other studies using injection techniques and Doppler measurements showed the measurements ranging from 1 to $1.5 \mathrm{~mm}$ and a median value of $2.3 \mathrm{~mm}$ respectively (PRIMAN, 1959; RAIO, GHEZZI, DI NARO et al., 2001).

The proportion of umbilical cords with a left twist $(80.7 \%)$ was much greater than those with a right twist $(19.3 \%)$. This is in concurrence with previous studies in which the prevalence of left twist varied from 65 to $79 \%$ (DE LAAT, FRANX, BOTS et al., 2006). The EI and CCI showed trends of a decrease and increase respectively with a right twist. This was similar to the association of the indices with the diameter of HA. The lack of statistical significance between right and left twist could be attributed to the relatively small sample size of the umbilical cords with a right twist. It is well documented that a right twist is more commonly associated with placenta previa and a single umbilical artery (BAERGEN, 2005). Thus it is possible that a right twist could influence the EI and CCI.

The focus of the present study was the association between the diameters of $\mathrm{HA}$ and direction of umbilical cord twists with the EI and CCI. However a number of other factors which could influence these indices were not studied. This is one of the limitations of the present study. Additional studies with larger sample size and including other independent variables need to be performed to further elucidate the factors governing the values of EI and CCI.

Acknowledgements: The authors would like to acknowledge the Department of Obstetrics and Gynecology for providing the placentae for the study. We would also like to acknowledge the faculty members, postgraduates and attendants of the Department of Anatomy for their support.

\section{References}

BAERGEN, R. N. Manual of benirschke and kaufmann's pathology of the human placenta. New York: Springer, 2005.

BIMPONG, S. Quantitative evaluation of umbilical cord and placental indices and pregnancy outcome. Kumasi: Kwame Nkrumah University of Science and Technology, 2012. [Master's Thesis].

DE LAAT, MW., FRANX, A., BOTS, ML., VISSER, GH. and NIKKELS, PG. Umbilical coiling index in normal and complicated pregnancies. Obstetrics and Gynecology, 2006, vol. 107, n. 5, p. 1049 1055. http://dx.doi.org/10.1097/01.AOG.0000209197.84185.15. PMid:16648410.

FINBERG, HJ. Avoiding ambiguity in the sonographic determination of the direction of umbilical cord twists. Journal of Ultrasound in Medicine, 1992, vol. 11, n. 5, p. 185-187. PMid:1588686.

PATHAK, S., HOOK, E., HACKETT, G., MURDOCH, E., SEBIRE, NJ., JESSOP, F. and LEES, C. Cord coiling, umbilical cord insertion and placental shape in an unselected cohort delivering at term: relationship with common obstetric outcomes. Placenta, 2010, vol. 31, n. 11, p. 963-968. http://dx.doi.org/10.1016/j. placenta.2010.08.004. PMid:20832856.

PRIMAN, J. A note on the anastomosis of the umbilical arteries. The Anatomical Record, 1959, vol. 134, n. 1, p. 1-5. http://dx.doi. org/10.1002/ar.1091340102. PMid:14434906.

QIN, Y., LAU, TK. and ROGERS, MS. Second-trimester ultrasonographic assessment of the umbilical coiling index. Ultrasound in Obstetrics \& Gynecology, 2002, vol. 20, n. 5, p. 458-463. http://dx.doi. org/10.1046/j.1469-0705.2002.00846.x. PMid:12423482.

RAIO, L., GHEZZI, F., DI NARO, E., FRANCHI, M., BALESTRERI, D., DURIG, P. and SCHNEIDER, H. In-utero characterization of the blood flow in the Hyrtl anastomosis. Placenta, 2001, vol. 22, n. 6, p. 597-601. http://dx.doi.org/10.1053/plac.2001.0685. PMid:11440549.

RAIO, L., GHEZZI, F., DI NARO, E., GOMEZ, R., SAILE, G. and BRUHWILER, H. The clinical significance of antenatal detection of discordant umbilical arteries. Obstetrics and Gynecology, 1998, vol. 91, n. 1, p. 86-91. http://dx.doi.org/10.1016/S0029-7844(97)005437. PMid:9464727.

ROBINSON, LK., JONES, KL. and BENIRSCHKE, K. The nature of structural defects associated with velamentous and marginal insertion of the umbilical cord. American Journal of Obstetrics and Gynecology, 1983, vol. 146, n. 2, p. 191-193. http://dx.doi.org/10.1016/00029378(83)91052-9. PMid:6846437.

SALAFIA, CM., YAMPOLSKY, M., MISRA, DP., SHLAKHTER, O., HAAS, D., EUCKER, B. and THORP, J. Placental surface shape, function, and effects of maternal and fetal vascular pathology. Placenta, 2010, vol. 31, n. 11, p. 958-962. http://dx.doi.org/10.1016/j. placenta.2010.09.005. PMid:20933281.

ULLBERG, U., LINGMAN, G., EKMAN-ORDEBERG, G. and SANDSTEDT, B. Hyrtl's anastomosis is normally developed in placentas from small for gestational age infants. Acta Obstetricia et Gynecologica Scandinavica, 2003, vol. 82, n. 8, p. 716-721. http:// dx.doi.org/10.1034/j.1600-0412.2003.00161.x. PMid:12848642.

YAMPOLSKY, M., SALAFIA, CM., SHLAKHTER, O., HAAS, D., EUCKER, B. and THORP, J. Modeling the variability of shapes of a human placenta. Placenta, 2008, vol. 29, n. 9, p. 790-797. http:// dx.doi.org/10.1016/j.placenta.2008.06.005. PMid:18674815.

Received July 17, 2014 Accepted November 18, 2015 